Journal of Experimental and Clinical Medicine https://dergipark.org.tr/omujecm

Case Report

J Exp Clin Med

2021; 38(3): 381-382

doi: $10.52142 /$ omujecm.38.3.33

\title{
A case of multiple trauma and lighter gas inhalation
}

\author{
Hatice Şeyma AKÇA
}

Department of Emergency Medicine, Ümraniye Education and Research Hospital, University of Health Sciences, Istanbul, Turkey

\begin{tabular}{l}
\hline Received: $25.05 .2020 \bullet \quad$ Accepted/Published Online: 06.02 .2021 \\
\hline Abstract \\
The rate of volatile substance abuse is increasing among young people around the world. A 10 -year-old boy was brought to the emergency room \\
by the 112-emergency ambulance service due to fall from the roof of a four-storey building. His general medical condition was moderate-poor; \\
his GCS (Glasgow Coma Scale) was nine, blood pressure: $118 / 90 \mathrm{mmHg}$, heart rate: $98 / \mathrm{min}, \mathrm{O}_{2}$ saturation was: $100 \%$. Skin abrasions were \\
present on his jaw and the occipital region of the scalp. The patient was accepted as a multiple trauma patient. When the patient's confusion did \\
not resolve, the patient's father informed us that the child may have inhaled lighter gas. The patient was hospitalized at the pediatric ward and was \\
discharged on the $14^{\text {th }}$ day of admission as his symptoms completely improved. Clinicians should be alert with regard to acute and/or chronic end- \\
organ damages in the cases of gas inhalation without any antidote.
\end{tabular}

Keywords: confusion, multiple traumas, substance abuse

\section{Introduction}

The rate of volatile substance abuse is increasing among young people in Turkey, as well as around the world. One of these abuses is lighter gas LPG (liquefied petroleum gas), which is easily available and cheap. Lighter gas contains butane, which is a volatile gas in the aliphatic hydrocarbon group (Altındağ et al., 2001; Öncü et al., 2014). It is sold commercially as propane, butane or propane-butane mixed gas. Propane is an odorless, colorless, flammable gas. Butane is a colorless, flammable gas and has a smell resembling gasoline or natural gas (Ruth, 1986; Büyük et al., 2005). The inhaled gas is absorbed from the alveolar surface and rapidly enters the blood and may cause dizziness, nausea, vomiting, euphoria, confusion, and hallucinations (Broussard, 1999; Öncü et al., 2014). We aimed to present the cigarette lighter gas inhalation case of a 10-year-old boy who was brought to our hospital by the 112-ambulance service due to multiple traumas.

\section{Case report}

A 10-year-old boy was brought to the emergency room by the 112-emergency ambulance service due to fall from the roof of a 4-storey building. His general medical condition was moderate-poor; he was confused, his GCS (Glasgow Coma Scale) was 9 . The blood pressure was $118 / 90 \mathrm{mmHg}$, heart rate was $98 \mathrm{bpm}, \mathrm{O}_{2}$ saturation was $100 \%$, and his four limbs were moving. Skin abrasions were present on his jaw and the occipital region of the scalp. The patient was accepted as a multiple trauma patient. He had no chronic illness in his medical history and no drug or substance abuse either.
Intravenous (i.v.) access was achieved and i.v. fluid support treatment was started. Panoramic CT scan was requested. Arterial blood gas (ABG) analysis revealed the serum $\mathrm{pH}$ as 7.27, $\mathrm{pCO}_{2}: 47 \mathrm{mmHg}, \mathrm{HCO}_{3}: 19.6 \mathrm{mmol} / \mathrm{L}$, glucose: 153 $\mathrm{mg} / \mathrm{dL}$ and lactate: $2.9 \mathrm{mmol} / \mathrm{l}$. Cohb:4. Liver and kidney function tests were normal. $\mathrm{Hg}$ level was $10.8 \mathrm{~g} / \mathrm{dl}$ and Htc was $32.1 \%$, which did not decrease during follow-up. ABG followup revealed that acidosis had improved. CT scan images were interpreted as normal. When the patient's confusion did not resolve, the patient's father informed us that the child may have inhaled lighter gas. The patient was consulted with brain surgery, orthopedics, and pediatric surgery and no traumatic pathology was detected. The patient was hospitalized at the pediatric ward. Urine buprenorphine and ecstasy levels were found to be low-positive in urine multi-drug analysis test result. On the $3^{\text {rd }}$ day of hospitalization, cranial MRI was requested due to persistent lethargy. Brain edema was observed in the occipital region. Emergency intervention was not considered in the patient who underwent the consultation of brain surgery. Anti-edema treatment and i.v. hypertonic saline infusion was initiated. No pathology was detected on EEG recordings. The patient was discharged on the $14^{\text {th }}$ day of admission as his symptoms completely improved.

\section{Discussion}

Butane gas has several acute and long-term effects. Acute irritability, cough, rhinorrhea, euphoria, and nausea may be seen in the early period of inhalation. Speech disorder, 
headache, confusion, delirium, hallucinations and decline in reflex responses require attention and close follow-up. Hypoxia, tachycardia, tinnitus, and nystagmus can also be seen at an early stage. Arrhythmias, hypoxia, asphyxia, and cardiac arrest may develop suddenly. While it may have cardiovascular, renal, pulmonary, and hematological effects in long term, it also has neurological and psychiatric long-term effects as well (Seven et al., 2017).

Our patient was brought to the ER due to multiple trauma and no intracerebral hemorrhage or any traumatic cerebral problem was considered on the first examination. Cranial CT imaging was normal and the patient who had undergone a neurosurgery consultation, did not have any acute pathology requiring surgical intervention due to trauma. Follow-up CT scans did not change the clinical approach. The acidosis in the blood gas analysis improved within a few hours after supportive treatment, the patient tended to sleep and he had severe headache at each awakening, which supported substance abuse. Although we questioned him on admission to the hospital, we were informed by his father 2 hours later. We believe that this case is important in terms of demonstrating the need to keep in mind the toxicological events regardless of the pre-diagnosis, especially volatile substance inhalation, in patients admitted with confusion, drowsiness or severe headache. Lighter gas inhalation is known to be more frequent in adolescents, especially in families with low socioeconomic status and psychiatric problems (Carlini-Catrim and Corlini, 1989; Carlini-Catrim, 1995; Frederich et al., 1997; Öncü et al., 2014). Similar features were present in our case. A 14-year-old girl was reported to develop dizziness and confusion after lighter gas inhalation. Since her vital signs and routine biochemical tests were normal, she was discharged 24 hours after admission (Öncü et al., 2014).

\section{References}

1. Akcan, R., Çekin, N., Hilal, A., Arslan, M.M., 2010. Sudden death due to inhalant abuse in youth: Case report. Dicle Med. J. 37, 154156.

2. Altındağ, A., Özkan, M., Oto, R., 2001. Inhalant related Disorders. Bull Clin Psychopharmacol. 11, 143-148.

3. Broussard, L., 1999. Inhalants: classification and abuse. In Levine BS., Principles of forensic Toxicology. American Association for Clinical Chemistry Inc. 345-353.

4. Büyük, Y., Yüksek, A., H., Eke, M., Bulut, E.R., Gürpınar, S., 2005. Suicide by inhalation of suffocative gas. Bullet. Leg. Med. $10,100-104$.

5. Carlini-Catrim, B., 1995. Inhalant use among Brazilian youths. NIDA Res. Monogr. 148, 64-78.

6. Carlini-Catrim, B., Corlini, E.A., 1989. The use of solvents and otherv drugs among children and adolescents from a low socioeconomic background: a study in San Paulo Brazil. Int. J. Ad dict. 84, 647-652.

7. Döring, G., Baumeister, F.A.M., Peters, J., Von Der Beek, J., 2002. Butane abuse associated Encephalopathy. Clin Pediatr. 214, 295-298.
A sudden death case of 19-year-old woman was reported, which occurred within 3-4 minutes after lighter gas inhalation. Another case of sudden death resulting from LPG inhalation for suicidal purposes was published in forensic medical journals (Büyük et al., 2005; Akcan et al., 2010). In a postmortem examination, a 15-year-old girl was found to have myocardial necrosis associated with butane gas (Aytül and Taner, 2019). An autopsy report of a 16-year-old boy after sudden death revealed edema in his brain and the cerebellum (Petekkaya et al., 2016). Brain edema detected in our patient two days after admission to ER was not considered because of trauma. Diffuse alveolar hemorrhage was reported in a 21year-old male due to chronic substance inhalation and encephalopathy was reported in a 15-year-old girl as well (Döring et al., 2002; Yavuz et al., 2018). It is thought that acute ischemia can be seen, although it is rare, secondary to trauma (Kolbaş et al., 2020). Our patient had no acute ischemia on MR imaging. In the previously reported cases and studies, we noticed that a history of lighter gas inhalation was present in the patient's anamnesis. To the best of our knowledge, there is no such case of lighter gas inhalation concomitant with trauma. Furthermore, we did not find any case of children 10 years or younger among reported cases and studies. Clinicians should be alert with regard to acute and/or chronic end-organ damages in the cases of gas inhalation without any antidote, who are treated by supportive treatment. Otherwise, in cases with different preliminary diagnoses, this may lead to follow-up in the emergency department and delay in hospitalization at the related ward.

\section{Conflict of interest}

None to declare.

\section{Acknowledgments}

None to declare.

8. Frederich, M., Mackusy-Ami, ME., Müskan, J.S., Goldstein, P.J., 1997. Childhood abuse and the use of inhalants: diferences by degree of use. Am. J. Public Health. 87, 765-769.

9. Kolbaş, F., Akça, H.Ş., Özdemir, S., Altunok, İ., Alp, H., Eroğlu, S., 2020. Ischemic stroke after head trauma in a child: case report. IJMRCR. 4, 132-134.

10. Öncü, S.B., Güzel, A., Paksu, Ş., Şahin, S., Suna, F., Yüce, M., 2014. Lighter Gas Inhalation: A Case Report. J. Pediatr. Emerg. Intens. Care Med. 1, 101-103.

11. Petekkaya, S., Ayaz, N., Dogan, M., Oruc, M., Oner, B.S., Gokturk, C et al., 2016. A Case of Sudden Death due to Lighter Refill Gas Inhalation. J. Turgut Ozal Med. Cent. 23, 107-110.

12. Ruth, J.H., 1986. Odor thresholds and irritation levels of several chemical substances: a review. Am. Ind. Hyg. Assoc. J. 47, $142-$ 151 .

13. Seven, E., Horoz, U., Sarı, E., Özakpınar, H.R., Sandıkcı, M.M., İnözü, E et al., 2017. A rare type of burn injury due to butane gas inhalation. TJTES. 23, 212-216.

14. Yavuz, M.Y., Anar, C., Alıcı, İ.O., Güldaval, F., Yücel, N., Büyükşirin, M., 2018. A Rare Case of Diffuse Alveolar Hemorrhage Secondary to Lighter Gas Inhalation. Respir. Case Rep. 7, 145-148. 